\title{
DISCUSSION.
}

\section{JUDGMENT AS "THE COLLECTIVE BECOMING ABSTRACT."}

The articles by M. Egger in the Revue Philosophique for July and August upon 'Judgment and Similarity' are a striking illustration of that most salutary psychological law that every one who thinks is sure to refute himself. He says that the judgment is not contained even potentially in the concept, although it is evident that the chief object of his articles is to get the concept out of the judgment. Strange that he fails to see how real his success is. Also he opposes those who have asserted the reducibility of association by contiguity to that by similarity, but says himself that all judgments are associations by similarity, and this, unless I be very much mistaken, is exactly what his imaginary foes have always meant. Throughout M. Egger builds more wisely than he knows.

'The collective idea becoming abstract,' which is M. Egger's definition of the judgment, is just what modern psychology means by conception. M. Egger unfortunately thinks of a concept rather than of conception, and from the concept, as the abstract idea or logical class, which, like its blood-relations, the idea-centre and the spiritual soul, has been exiled from psychology, it is not strange that he is unable to derive the judgment.

The abstract idea, that passed for the concept so long, was the unifying principle of a manifold of experiences. As Kant could write of space as a priori form, before the psychology of space as founded on movement or action, on the association of muscular sensations and 'local signs,' had been reported, so in general the abstract idea, as a formal principle, could be recognized and seriously used in psychological theory, before the processes of organic functioning, as the subject-matter of physiology, were exposed. But, just as now a priori space means nothing but the power of perfectly free movement, so the abstract idea, as a principle of unity, stands for free action; the abstract idea is not an idea at all, but an act : conception, from being 
classification, has become organization; it is co-ordination of, or adjustment to, not logical or abstract unification of, a manifold.

With this view of conception it is easy to see that $M$. Egger has hit upon a very important principle when he banishes all relations of extensity or contiguity to the terms of the judgment, refusing to recognize any but judgments by similarity, the copula naming only similarity. As he says, with less emphasis than we could wish, the process of judgment has too long been explained through its merely external expressions in language, in some particular language of course, in French, or English perhaps, or German, so that the differences between thinkers have had rather a grammatical than a psychological basis. The judgment makes but is not the sentence. Also,--and here is an idea only very darkly and deeply implied in M. Egger's final definition of judgment, - so long as words, sentences, and the like are conditions or incidents of judgment, the act of judgment, as, for example, the assertion that $A$ is $B$, is as much a judgment of space as my now seeing yonder chair in the corner of my study is a judgment of space. Surely all symbols are spatial. The concept element, then, in any judgment is the functional movement or adjustment that the symbol represents. The terms of any judgment are the inhibited movements, or rather the organization or adjustment, which demands the inhibitions, as attribute or predicated quality - the ' abstract idea' of former days, and the spatial images, symbols, or characters which the inhibitions bring to consciousness as subject or substantive. Moreover, within the subject properly belong all the facts of spatial relationship or quantity or contiguity.

The judgment defined as the collective becoming abstract is but another way of saying that the limit of conception is second nature or habit, and that, so long as habit is not yet acquired, the judgment, that is, consciousness in general, exists. So long as habit is not acquired there is a tension between substantive and attribute, between spatial symbol and the 'abstract' organizing act; with the acquisition the judgment passes into a definition.

As geometry is the complete definition of space, and as it is a possible science only to such organisms as possess the fully developed power, or habit, of free movement, so definitions in general, in which both subject and predicate are quantified, the tension having ceased, are real, or possible, only to such natures as have reallized the freedom which is defined. Science in general, as purely quantitative, has its psychological foundation in habit, freedom, perfected adjustment.

In conclusion, and with some repetition, the real judgment is always the consciousness; it is not, as logicians and psychologists, even $M$. 
Egger among the others, in spite of his coming so near to the truth, have usually imagined, the external sentence, which may interest the grammarian, but is sure to mislead the philosopher who looks no deeper. Language is no longer the heaven-sent blessing that we used to imagine it. But, secondly, the judgment in consciousness is a tension, a 'becoming,' which has its 'abstract' limit in the definition. The tension, finally, as between the abstract idea, or quality, one extreme of M. Egger's natural judgment, and the collective and substantial object, which contains within itself more or less precisely determined spatial relations of contiguity and quantity, and is the other extreme, ceases as the concept becomes realized in habit. Of course habit, as the realized concept, the acme of abstraction, is one and the same with definition; it sets or establishes the relations on which all science of the contiguous and quantitative rests.

A. H. LLOYD.

UNIVERSITY OF MichIGAN. 